\title{
Fabrication of Al-Coated Mg-Li Alloy Sheet and Investigation of Its Properties
}

\author{
Tian-Long Zhang ${ }^{1} \cdot$ Toko Tokunaga $^{2} \cdot$ Munekazu Ohno $^{2} \cdot$ Mi-Lin Zhang $^{3} \cdot$ Kiyotaka Matsuura $^{2}$
}

Received: 5 April 2018/Revised: 8 May 2018/Published online: 26 June 2018

(C) The Chinese Society for Metals and Springer-Verlag GmbH Germany, part of Springer Nature 2018

\begin{abstract}
An Al-coated Mg-8 mass\% Li alloy rectangular bar was fabricated by hot extrusion, and then, it was hot-rolled into a thin sheet. The Al coating was uniform in thickness and had good bonding with the substrate during all the processing. This Alcoated $\mathrm{Mg}-\mathrm{Li}$ alloy exhibited a good corrosion resistance in a 0.5 mass $\% \mathrm{HCl}$ aqueous solution. No intermetallic compound was observed at the $\mathrm{Al} / \mathrm{Mg}-\mathrm{Li}$ interface after the extrusion and the rolling. The Al-coated $\mathrm{Mg}-\mathrm{Li}$ alloy sheet exhibited an elongation to fracture of $35 \%$ at room temperature at a strain rate of $0.001 \mathrm{~s}^{-1}$ without any debonding between the coating and the substrate. When tensile tested at $573 \mathrm{~K}_{\text {at }} 0.001 \mathrm{~s}^{-1}$ in the air, the $\mathrm{Al}$ coating remained undamaged even until an elongation of about $150 \%$. Further elongation generated cracks on the coating and the specimen fractured at an elongation of about $200 \%$. In an Ar atmosphere, the specimen exhibited a fracture elongation of over $400 \%$ under the same conditions at $573 \mathrm{~K}$ at $0.001 \mathrm{~s}^{-1}$, although a large number of cracks generated on the $\mathrm{Al}$ coating.
\end{abstract}

Keywords $\mathrm{Mg}-\mathrm{Li}$ alloy $\cdot$ Composite material $\cdot$ Coating $\cdot$ Mechanical properties $\cdot$ Superplasticity

\section{Introduction}

Light-weighting of engineering systems like vehicles and aircrafts can improve fuel efficiency. It is reported that $22.5 \mathrm{~kg}$ of mass reduction will improve fuel efficiency by around $1 \%$ in a typical car [1]. Therefore, development of lightweight structural materials is an important subject. Mg-based alloys with $\mathrm{Li}$ as a major alloying element, which are usually called $\mathrm{Mg}-\mathrm{Li}$ alloys, have significant low densities $\left(1.35-1.65 \mathrm{~g} \mathrm{~cm}^{-3}\right)$ compared with other structural metals such as $\mathrm{Al}\left(2.70 \mathrm{~g} \mathrm{~cm}^{-3}\right)$ alloys and $\mathrm{Fe}$ $\left(7.87 \mathrm{~g} \mathrm{~cm}^{-3}\right)$ alloys $[2,3] . \mathrm{Mg}-\mathrm{Li}$ alloy is the lightest structural metal in existing engineering alloy systems,

Available online at http://link.springer.com/journal/40195

Tian-Long Zhang

ztiantianl@hotmail.com

1 Graduate School of Engineering, Hokkaido University, Kita 13 Nishi 8, Kita-ku, Sapporo, Hokkaido 060-8628, Japan

2 Faculty of Engineering, Hokkaido University, Kita 13 Nishi 8, Kita-ku, Sapporo, Hokkaido 060-8628, Japan

3 College of Materials Science and Chemical Engineering, Harbin Engineering University, NO.145 Nantong Street, Harbin 150001, China which has high specific strength and good castability. Furthermore, compared with conventional $\mathrm{Mg}$ alloys, the plasticity of $\mathrm{Mg}-\mathrm{Li}$ alloys has a large improvement when the content of $\mathrm{Li}$ is higher than $5.5 \mathrm{wt} \%$, because the stable phase changes from hcp $(<5.5 \mathrm{wt} \% \mathrm{Li})$ to hcp/bcc $(5.5-10.3 \mathrm{wt} \% \mathrm{Li})$ and bcc ( $>10.3 \mathrm{wt} \% \mathrm{Li})$ [4].

However, the largest disadvantage of $\mathrm{Mg}-\mathrm{Li}$ alloys is their poor corrosion resistance. In addition, one of the most effective ways to prevent corrosion is coating. Conventional methods to produce coating are chemical methods, e.g., plating and anodizing [5-9]. However, $\mathrm{Mg}$ and its alloys are difficult to be coated by chemical methods for their active chemical properties [10]. To produce a good coating, complex procedures are usually needed, and sometimes, toxic solution is used.

Therefore, in this study, we attempted to produce a corrosion-resistant coating on $\mathrm{Mg}-\mathrm{Li}$ alloys by a hot extrusion method instead of chemical ways. Mechanical ways like rolling and extrusion to produce protective coating on $\mathrm{Mg}$ alloys were proved to be effective, efficient, and environmental friendly by removing chemical treatments [11-13]. Al was chosen, as the coating material in this study for it exhibits a very good corrosion resistance in ambient environment and is also light metal. An Al-coated $\mathrm{Mg}-\mathrm{Li}$ alloy is expected to exhibit a good corrosion 
resistance without losing the advantage of light-weighting. Normally, these two metals cannot be bonded simply with each other because of the existence of oxide films on their surfaces. We consider that the oxide films can be broken by a severe plastic deformation, due to the enormous difference of ductility between metal and metal oxide. In addition, subsequently, fresh metal surfaces come to the front. The new metal surfaces are severely deformed in contact with each other under a very high pressure to avoid reoxidation. Therefore, with the newly formed metal surfaces, the two metals can be strongly bonded. In addition, an $\mathrm{Al}$-coated $\mathrm{Mg}-\mathrm{Li}$ alloy bar was produced using the hot extrusion method in this study. After the extrusion, we rolled the Al-coated $\mathrm{Mg}-\mathrm{Li}$ alloy bar into thin sheet, because sheet is more widely used to produce various shapes. In addition, for a further forming of the sheet, its mechanical properties, especially plasticity, are of great research value. In the previous study, though this kind of $\mathrm{Al} / \mathrm{Mg}-\mathrm{Li}$ alloy/Al clad sheet was produced with good corrosion resistance, the debonding between coating and substrate during further deformation was the problem [11].

Therefore, as stated before, the good plasticity of $\mathrm{Mg}-\mathrm{Li}$ alloy is also an important reason for we choose it as the base alloy. Meanwhile, we noted that dual-phase $\mathrm{Mg}-\mathrm{Li}$ alloys were reported a lot to exhibit superplasticity after severe deformation [14-16]. Owing to the large deformation of superplasticity, now, many complex parts can be processed by superplastic forming [17-19]. Moreover, a non-superplastic $\mathrm{Al}$ coating was reported to be superplastically formed with an AZ80 Mg alloy substrate without breaking [20]. From these facts, it is expected that an Alcoated $\mathrm{Mg}-\mathrm{Li}$ alloy, which is our main focus, can also exhibit superplasticity with an unbroken $\mathrm{Al}$ coating. By superplastic forming, it is expected to process the Alcoated $\mathrm{Mg}-\mathrm{Li}$ alloy sheet into a variety of desired shapes.

Thus, the aim of this study is to investigate (1) the feasibility of $\mathrm{Al}$ coating on an $\mathrm{Mg}-\mathrm{Li}$ alloy by a hot extrusion process, (2) effects of the $\mathrm{Al}$ coating on the corrosion resistance, and (3) mechanical properties and superplasticity of the Al-coated $\mathrm{Mg}-\mathrm{Li}$ alloy sheet.

\section{Experimental}

Figure 1 displays the schematic of the hot extrusion equipment. An $\mathrm{Mg}-\mathrm{Li}$ alloy billet was put in the bottom of the container, and a $5 \mathrm{~mm}$-thick Al plate (99.99 mass\% purity) was placed between the die and the $\mathrm{Mg}-\mathrm{Li}$ alloy billet. The Mg- 8.03 mass\% Li alloy was employed in this study. This composition was checked by an inductively coupled plasma atomic emission spectrometer (ICP-AES). The size and shape of the die are shown in Fig. 2. Before extrusion, the die and rams were pre-heated to $548 \mathrm{~K}$

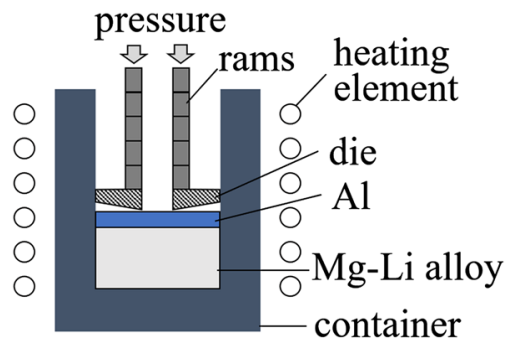

Fig. 1 Schematic of the hot extrusion equipment

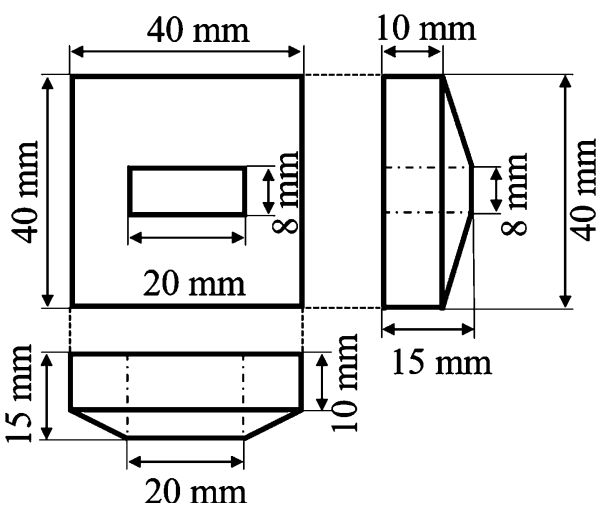

Fig. 2 Schematic of the die

outside the container, while the container was pre-heated to $473 \mathrm{~K}$. Then, the $\mathrm{Mg}-\mathrm{Li}$ alloy billet and the $\mathrm{Al}$ plate were put into the container. In addition, the die and rams were set above the Al plate, as illustrated in Fig. 1. After this setting, the temperature of the container was increased from 473 to $523 \mathrm{~K}$ and the extrusion was carried out. The pressure was $300 \mathrm{kN}$ and the extrusion speed was $0.6 \mathrm{~mm} /$ s. After extrusion, the as-extruded bar was cut every $10 \mathrm{~mm}$ in the longitudinal direction from the tip to the end to measure the thickness of the $\mathrm{Al}$ coating on the cross section. Five data measured on the long sides of rectangular cross section were chosen to calculate average.

The extruded bar was rolled from 8 to $1.5 \mathrm{~mm}$ in thickness at $523 \mathrm{~K}$ using a two-high mill. The rolling direction was parallel to the extrusion direction. After rolling, tensile specimens were cut from the as-rolled sheet using a wire electrical discharge machine. The dimensions of the tensile specimen are shown in Fig. 3. The tensile

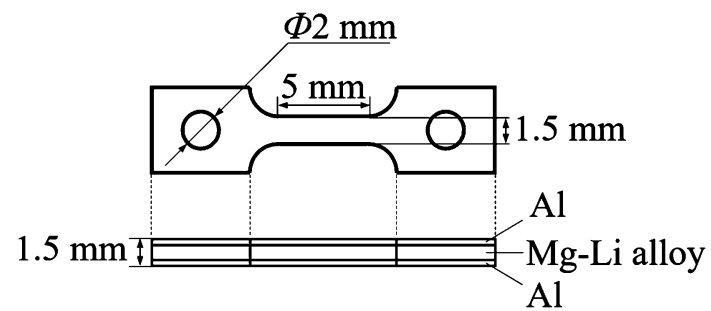

Fig. 3 Schematic drawings of tensile test specimen: a top view, b longitudinal section 
direction was parallel to the rolling and extrusion directions. Tensile tests were performed with the Instron tensile machine at room temperature at a strain rate of $0.001 \mathrm{~s}^{-1}$ in the air. High-temperature tensile tests were also performed at $573 \mathrm{~K}$ at a strain rate of $0.001 \mathrm{~s}^{-1}$ both in the air and in the an $\mathrm{Ar}$ atmosphere.

The microstructures of the as-extruded, as-rolled, and tensile-elongated samples were observed using an optical microscope $(\mathrm{OM})$. To distinguish $\alpha$ phase and $\beta$ phase in the $\mathrm{Mg}-\mathrm{Li}$ alloy substrate, some samples were etched with a mixture of picric acid of $32 \mathrm{~mL}$, acetic acid of $20 \mathrm{~mL}$, distilled water of $20 \mathrm{~mL}$, and ethyl alcohol of $18 \mathrm{~mL}$ before observation. The elements distribution and electron backscattering diffractions (EBSD) analyses were conducted by a JAMP-9500F Auger electron spectroscopy (AES). The fracture surfaces of the tensile specimens were observed by a JSM-6510LA scanning electron microscope (SEM).

The corrosion resistance was evaluated by an immersion test. Different samples were immersed in a 0.5 mass $\% \mathrm{HCl}$ aqueous solution for $90 \mathrm{~min}$ at room temperature and their weight losses per unit area was monitored during the immersion. Before immersion, the surfaces of each sample except the Al-coating surface were covered with resin, which does not react with the acid. For a comparison, $\mathrm{Mg}-$ $\mathrm{Li}$ alloy without $\mathrm{Al}$ coating and the pure $\mathrm{Al}$ were also subjected to this corrosion test.

\section{Results and Discussion}

\subsection{Feasibility of the Al-Coated Mg-Li Alloy Sheet}

Figure $4 \mathrm{a}$ shows the cross section of the as-extruded Alcoated $\mathrm{Mg}-\mathrm{Li}$ alloy. The Al-coating layer is uniformly coated on the surface of the Mg-Li alloy substrate. Figure $4 \mathrm{~b}$ illustrates the interface between Al-coating layer and $\mathrm{Mg}-\mathrm{Li}$ alloy substrate. In the $\mathrm{Mg}-\mathrm{Li}$ alloy substrate, the bright and the dark areas are $\alpha$ (hcp, Mg-rich) and $\beta$ (bcc, Li-rich) phases, respectively. From the figure, no cracks are observed at the interface, which suggest a good bonding at the interface. Moreover, there are no obvious intermetallic compound (IMC) layers forming at the interface which is beneficial to mechanical properties, because IMCs are generally brittle and deteriorate the mechanical properties of the composite. Figure 5 demonstrates the change of the Al-coating thickness in the longitudinal direction of the as-extruded bar. The thickness of the coating near the tip is particularly thick, because at the start of the extrusion, the thick Al plate covers the top of the $\mathrm{Mg}-\mathrm{Li}$ alloy billet. As the extrusion proceeds, the thickness of the coating becomes uniform and it was reduced to around $200 \mu \mathrm{m}$ at a position about $50 \mathrm{~mm}$ away from the tip.

Figure 6 shows the microstructures of the as-rolled Alcoated $\mathrm{Mg}-\mathrm{Li}$ alloy. The rolling direction corresponds to the traverse direction of the figure. The $\mathrm{Al}$ coating keeps uniform thickness in the rolling direction in Fig. 6a. The phases in the $\mathrm{Mg}-\mathrm{Li}$ alloy substrate are elongated along the rolling direction, especially $\beta$ phase (dark part in the $\mathrm{Mg}-$ $\mathrm{Li}$ alloy substrate in Fig. 6 b), and are severely elongated, because it is much more ductile than $\alpha$ phase (bright part in the $\mathrm{Mg}-\mathrm{Li}$ alloy substrate in Fig. 6b). Furthermore, cracks or IMC layers were not observed at the interface.

\subsection{Room Temperature Tensile Properties of the Al-Coated Mg-Li Alloy Sheet}

Figure 7 shows the stress-strain curves obtained from the tensile tests at room temperature. The as-rolled Al-coated $\mathrm{Mg}-\mathrm{Li}$ alloy sheet exhibits an ultimate tensile strength of
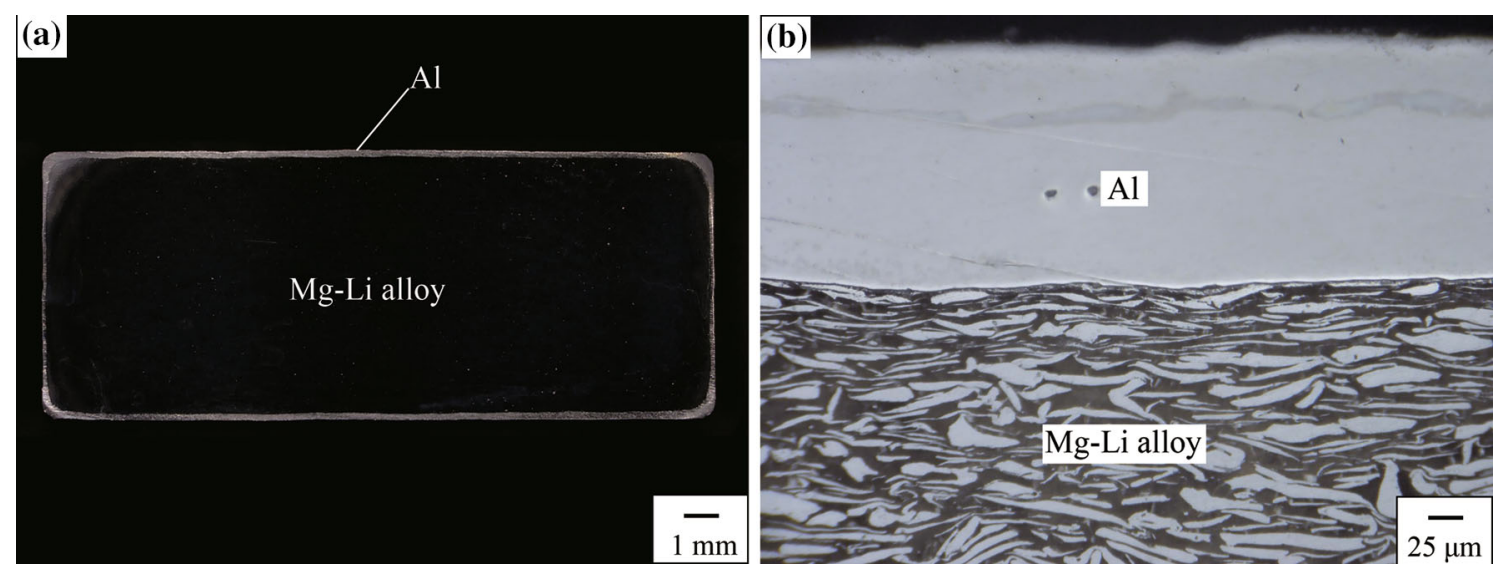

Fig. 4 a Cross section of the as-extruded Al-coated Mg-Li alloy rectangular bar which is about $50 \mathrm{~mm}$ from the tip, $\mathbf{b}$ interface between Al coating and $\mathrm{Mg}-\mathrm{Li}$ alloy substrate in the cross section. The extrusion direction corresponds to the normal to the figure 


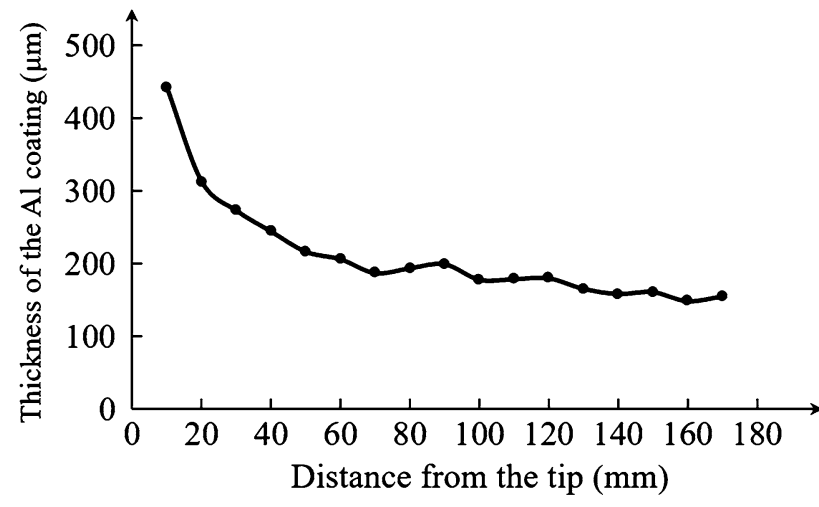

Fig. 5 Change of the coating thickness in the longitudinal direction of the as-extruded $\mathrm{Al}$-coated $\mathrm{Mg}-\mathrm{Li}$ alloy bar

about $160 \mathrm{MPa}$ and a fracture elongation of about $35 \%$. Figure 8 shows the longitudinal section of the fracture part of the tensile specimen, in which no cracks at the coating/substrate interface can be seen after the tensile elongation, which suggests that the deformation of the coating keeps good consistence with the deformation of the substrate. Finally, as more clearly shown in Fig. 8b, the coating exhibits a typical necking of a ductile material, while the substrate exhibits a slight degree of necking associated with a shear fracture.

And then, heat treatments were attempted to get a better plasticity. After a heat treatment at $573 \mathrm{~K}$ for $60 \mathrm{~min}$, the fracture elongation can be improved to about $45 \%$ as the illustrated by the red curve in Fig. 8, accompanied by a marked drop on strength. On the other hand, the growth of IMC at the interface is an undesirable consequence after heating, as shown in Fig. 9a, and IMCs are usually brittle and have bad influence on mechanical properties. Figure $9 \mathrm{~b}$ shows a line profile of the element distribution at the interface. Small platforms of the lines can be seen at the interface, suggesting the forming of the IMC. Notably, the

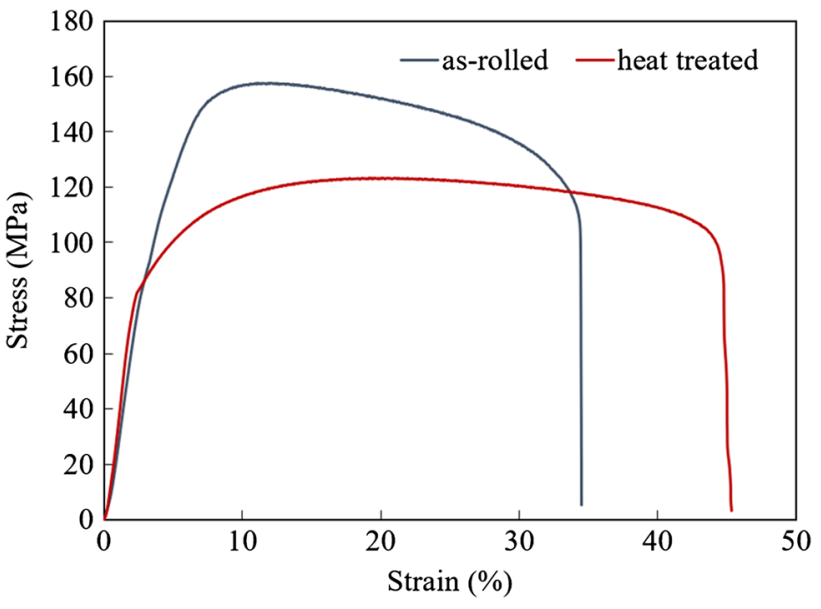

Fig. 7 Nominal stress-strain curves of the as-rolled Al-coated $\mathrm{Mg}-\mathrm{Li}$ alloy sheet at room temperature at $0.001 \mathrm{~s}^{-1}$

diffusion of Li does not stop at the interface like $\mathrm{Mg}$ and Al. It has diffused far into the $\mathrm{Al}$ coating. This will partly change the pure $\mathrm{Al}$ into an $\mathrm{Al}-\mathrm{Li}$ alloy.

Figure 10 shows the fracture surfaces of the specimens after tensile tests at room temperature. In Fig. 10a, without heat treatment, the $\mathrm{Al}$ coating has a sharp edge after fracture because of necking. In addition, there is a smooth surface of the $\mathrm{Al}$ coating on the side close to the $\mathrm{Mg}-\mathrm{Li}$ alloy. These are in agreement with the longitudinal section, as displayed in Fig. 8b. On the other hand, after a heat treatment at $573 \mathrm{~K}$ for $60 \mathrm{~min}$, the fracture surface of the $\mathrm{Al}$ coating becomes rough with a two-layered structure, as shown in Fig. 10b. As illustrated in Fig. 9a, the inner layer should be the IMC layer. In addition, the deep gap between the substrate and the IMC layer suggests that the fracture may preferentially start from the IMC layer or the IMC/ $\mathrm{Mg}-\mathrm{Li}$ interface because of the low ductility of the IMC.
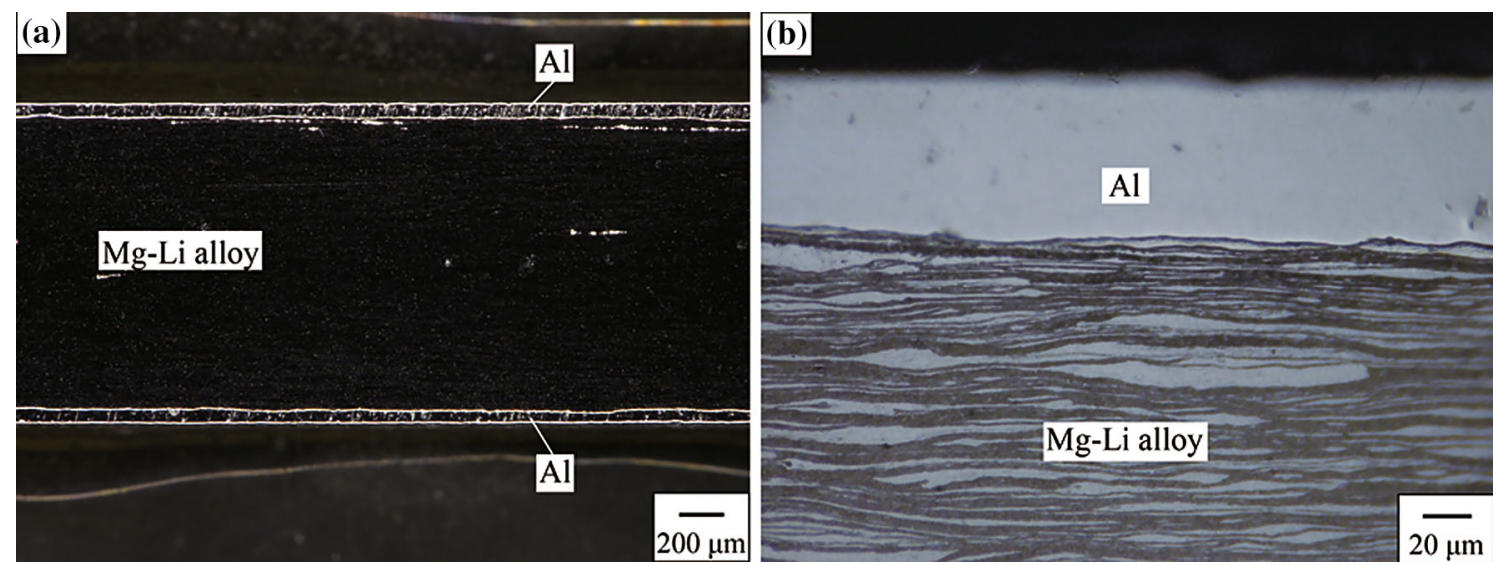

Fig. 6 a Longitudinal section of the as-rolled Al-coated Mg-Li alloy sheet, $\mathbf{b}$ interface between Al-coating and Mg-Li-alloy substrates in the longitudinal section. The rolling direction corresponds to the traverse direction of the figures 

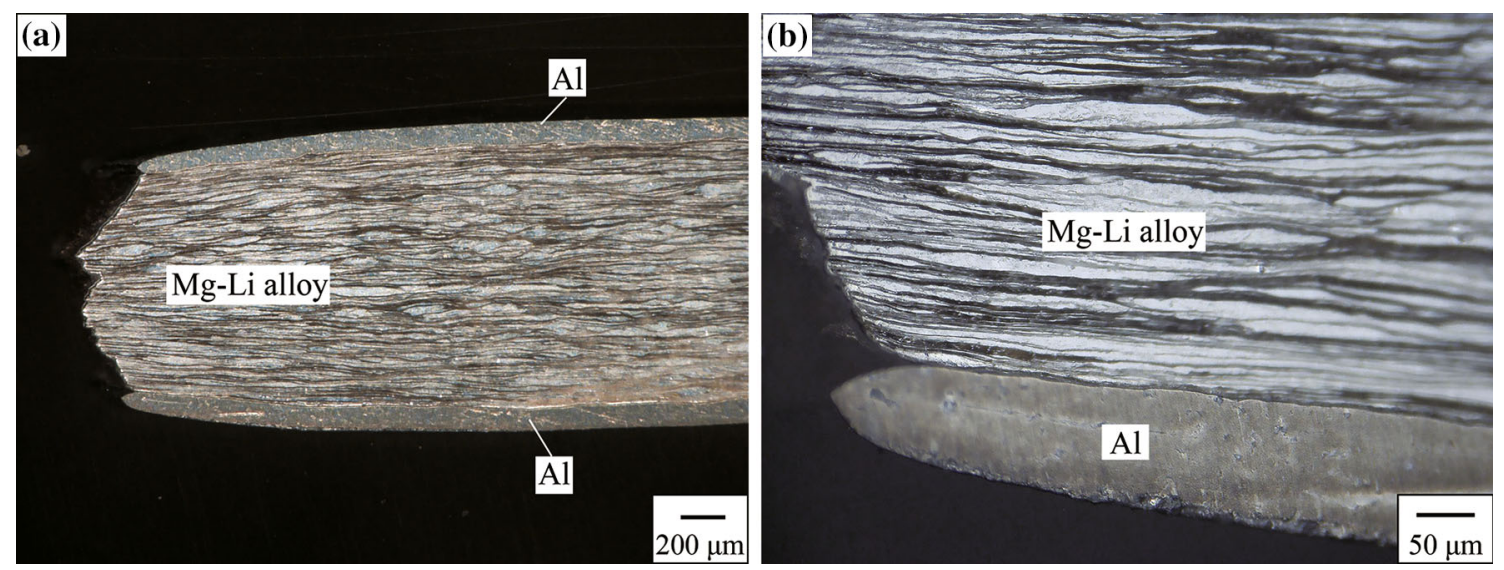

Fig. 8 Longitudinal section of the as-rolled Al-coated $\mathrm{Mg}-\mathrm{Li}$ alloy sheet elongated to fracture at room temperature: a low magnified image, b high magnified image of the Al-coating part
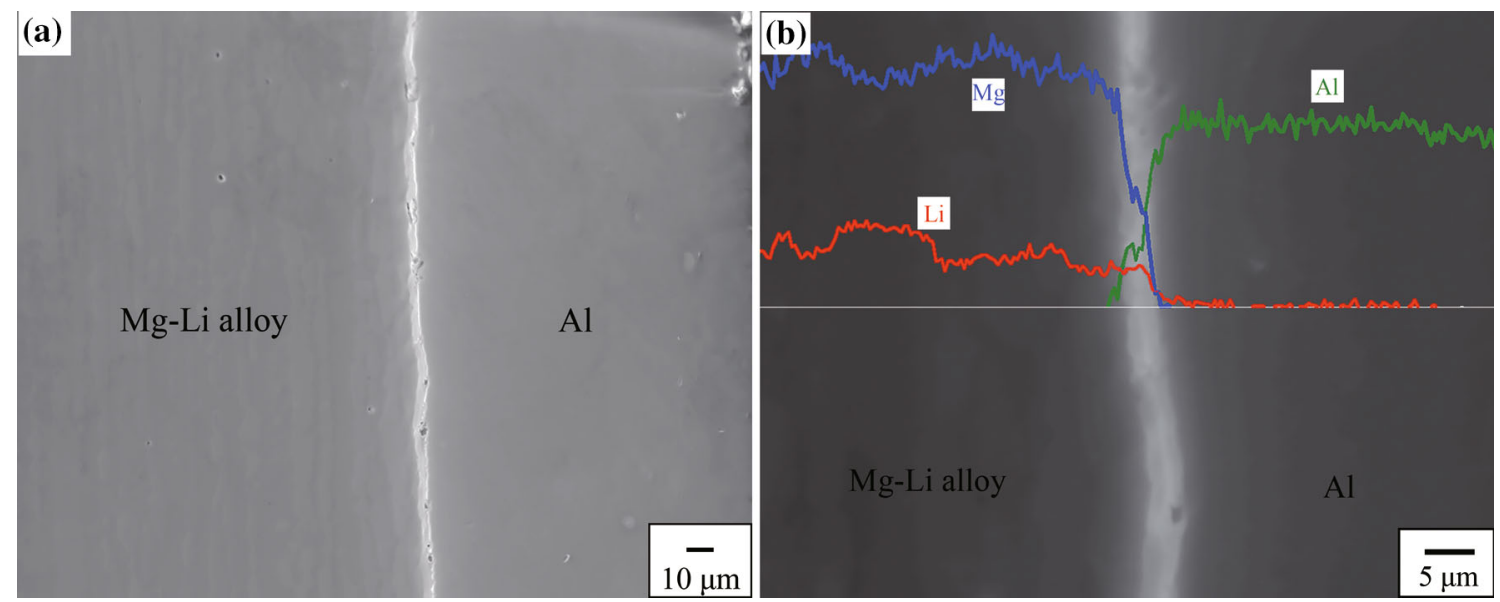

Fig. 9 a SEM image of the intermetallic compound layer, b AES line profile showing the distribution of $\mathrm{Li}, \mathrm{Mg}$ and $\mathrm{Al}$ at the $\mathrm{Al} / \mathrm{Mg}-\mathrm{Li}$ alloy interface after a heat treatment at $573 \mathrm{~K}$ for $60 \mathrm{~min}$
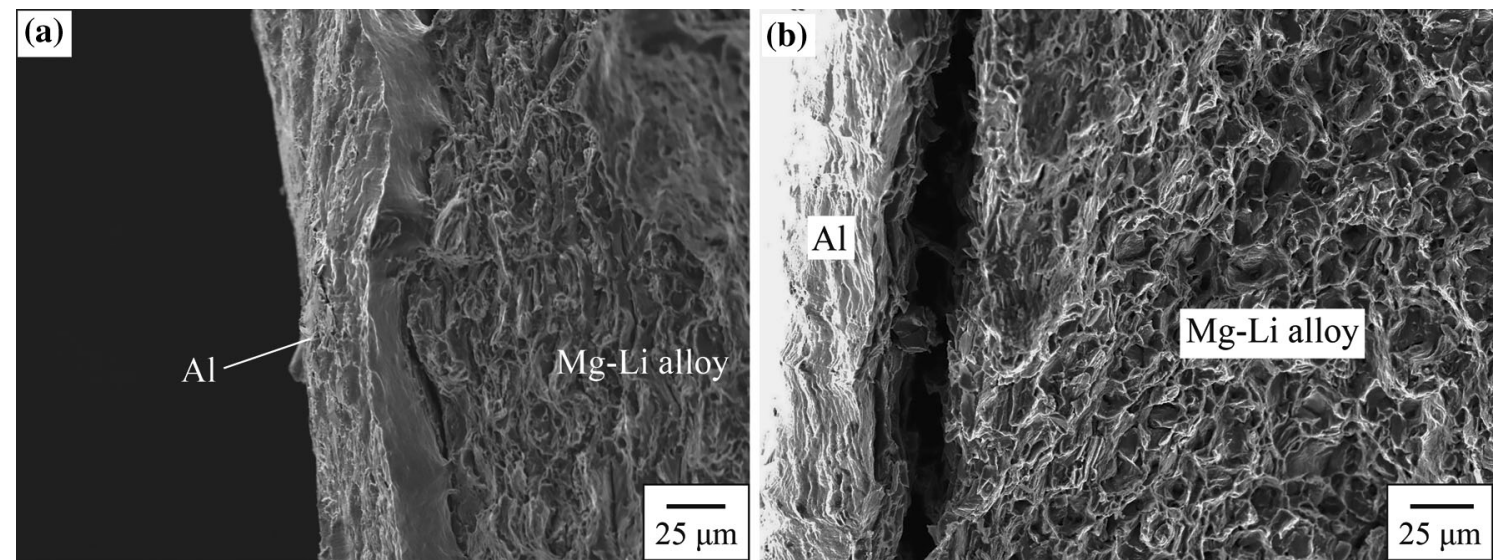

Fig. 10 SEM images of the tensile fracture surface of the specimen: a as-rolled specimen without heat treatment, $\mathbf{b}$ specimen after a heat treatment at $573 \mathrm{~K}$ for $60 \mathrm{~min}$ 


\subsection{Superplasticity of the Al-Coated Mg-Li Alloy Sheet}

Figure 11 illustrates the EBSD grain and phase image of the as-rolled Al-coated Mg-Li alloy specimen just before the superplastic tensile test starting at $573 \mathrm{~K}$, which is in fact a specimen after a heat treatment at $573 \mathrm{~K}$ for $10 \mathrm{~min}$ according to the experimental procedures. In the grain map in Fig. 11a, in the Mg-Li alloy substrate, grains of both $\alpha$ and $\beta$ phases are elongated along the rolling direction: the width of the elongated grain in the normal direction is less than $10 \mu \mathrm{m}$, while the lengths of many grains in the rolling direction are larger than $20 \mu \mathrm{m}$. The grains of $\mathrm{Al}$ are equiaxed and are most less than $10 \mu \mathrm{m}$ in size.

Figure 12 a shows the stress-strain curves of the specimens tensile tested at different temperatures from 448 to $573 \mathrm{~K}$ at $0.001 \mathrm{~s}^{-1}$. At above $473 \mathrm{~K}$, the specimens can exhibit fracture elongations of about $200 \%$, while at $448 \mathrm{~K}$, the fracture elongation decreases to about $170 \%$. In addition, as testing temperature rising, the flow stress falls dramatically. On the other hand, Fig. 12b shows the stressstrain curves at the same temperatures at the strain rate of $0.01 \mathrm{~s}^{-1}$. Compared with Fig. 12a, flow stresses are larger at the same temperature in Fig. 12b, while the fracture elongation decreases by about $50 \%$ at every temperature.

In Fig. 12a, oscillations can be observed on all the curves, which means that hardening stage and softening stage alternatively occur during the tensile process. Dynamic recrystallization (DRX) is an important softening mechanism during the hot deformation of $\mathrm{Mg}-\mathrm{Li}$ alloy [21]. Comparing Fig. 12a, b, the softening stages are obvious in (a) at lower strain rate, while no large rise and fall can be observed in (b) at rather high strain rate. This is because that DRX is a process induced by atomic diffusion [22]: at lower strain rate in Fig. 12a, it takes relatively long time to reach the same strain, and then, there is enough time for diffusion to induce the DRX, and in Fig. 12b, at very high strain rate, there is little time for diffusion; therefore, we cannot see an obvious softening stage caused by DRX.

The superplastic deformation can be described by the model as follows [23]:

$\sigma=k \dot{\varepsilon}^{m}$,

where $\sigma$ is the flow stress, $\dot{\varepsilon}$ is the strain rate, constant $k$ depends on composition, microstructure, and temperature, and $m$ is the index of strain rate sensitivity. The $m$ value is important in describing the behavior of superplastic deformation. In addition, a large $m$ value usually means a large superplastic elongation. A typical superplasticity is characterized by an $m$ value of more than 0.3 [24]. In addition, according to the above equation, the $m$ value can be calculated by the slope of a double logarithmic plot of flow stress versus strain rate:

$m=\frac{\partial \ln \sigma}{\partial \ln \dot{\varepsilon}}$.

Therefore, the $m$ values of the Al-coated $\mathrm{Mg}-\mathrm{Li}$ alloy sheet at different temperatures are calculated shown in Fig. 13. It is obvious that the $m$ value increases as the temperature rising. In addition, the largest value is 0.38 at $573 \mathrm{~K}$. Notably, the value of $m$ falls greatly from 0.32 to 0.25 when temperature decreases from 473 to $448 \mathrm{~K}$. This is in consonance with the tensile results in Fig. 12, where obvious fall of elongation can be seen when temperature drops to $448 \mathrm{~K}$.

On the other hand, when temperature is higher than $473 \mathrm{~K}$, the fracture elongations are almost the same, though the $m$ value changes. In fact, we found that cracks always occurred on the Al coating after the specimen was elongated to about $150 \%$ no matter the temperature.

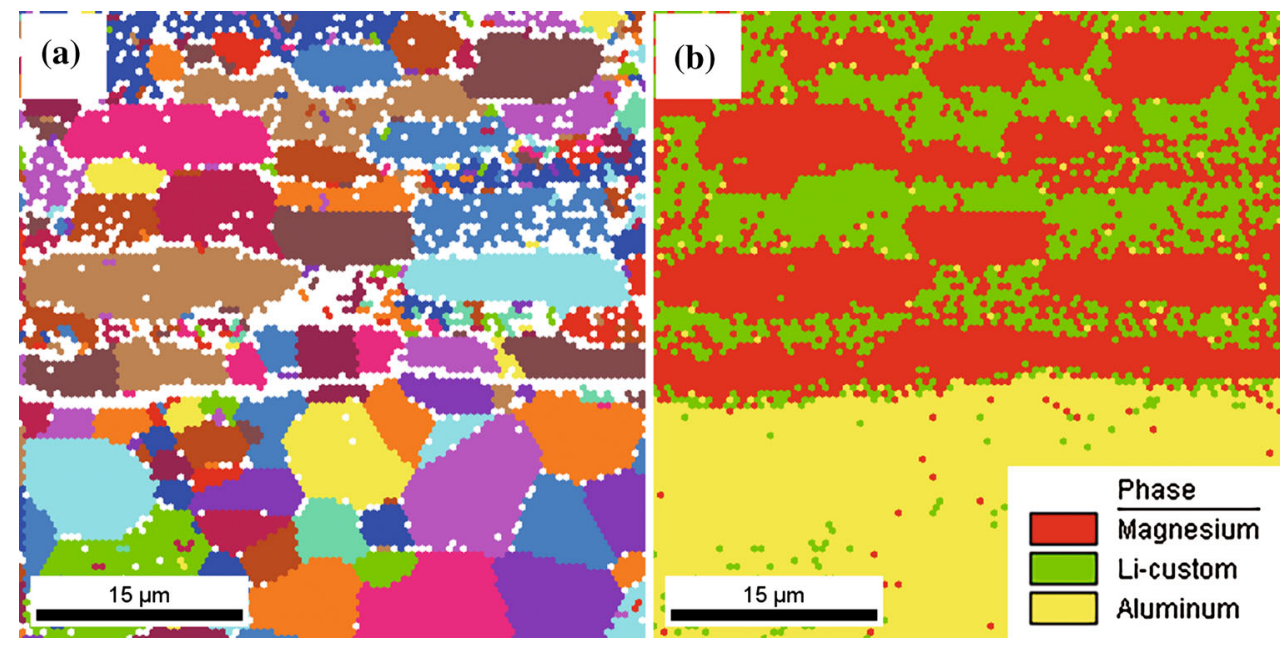

Fig. 11 EBSD image of the specimen before superplastic tensile test: a grain map, $\mathbf{b}$ phase map 

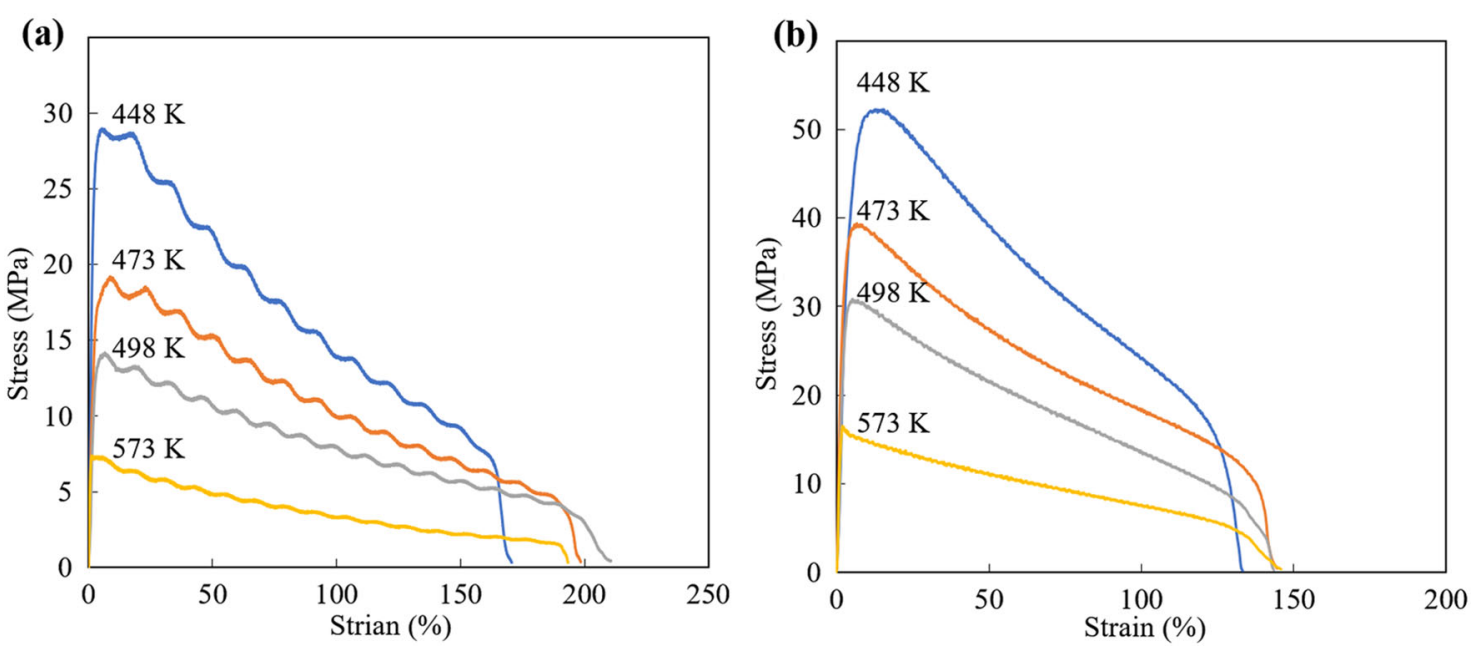

Fig. 12 Stress-strain curves of the specimens tensile tested at temperatures from $448 \mathrm{~K}$ to $573 \mathrm{~K}$ in the air at strain rates of a $0.001 \mathrm{~s}^{-1}$, b $0.01 \mathrm{~s}^{-1}$

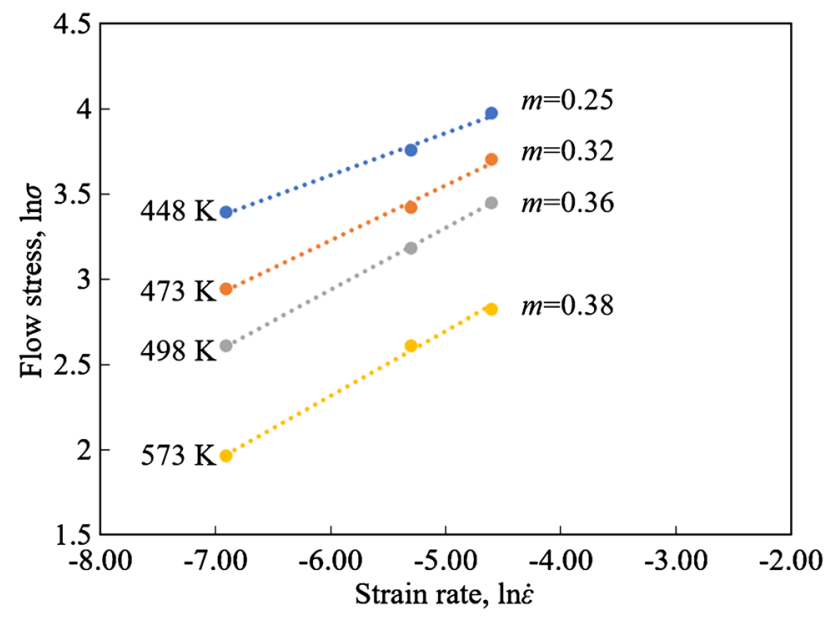

Fig. 13 Effects of strain rate on the flow stress of the Al-coated $\mathrm{Mg}-$ $\mathrm{Li}$ alloy sheet at different temperatures

Figure 14 shows the longitudinal section of the specimen after an elongation of $150 \%$ at $573 \mathrm{~K}$ at $0.001 \mathrm{~s}^{-1}$. Though the $\mathrm{Al}$ coating is unbroken, some small necking parts can be seen. When the tensile test continued to larger than $150 \%$ elongation, cracks started to generate on the $\mathrm{Al}$ coating, and consequently, the specimen fractured at an elongation of about $200 \%$ in the air, as shown in Fig. 15. On the other hand, when tested in an Ar atmosphere, the fracture elongation increases to more than $400 \%$. If observed carefully, there are many cracks on the $\mathrm{Al}$ coating of the specimen deformed in an Ar atmosphere. In contrast, the specimen deformed in the air has a small number of cracks only near the fracture part. The oxidation of the $\mathrm{Mg}-\mathrm{Li}$ alloy during superplastic deformation in high-temperature air has been reported in some researches [25, 26]. In the case of this study, after a crack appears on the Al coating, the $\mathrm{Mg}-\mathrm{Li}$ alloy substrate becomes exposed to the

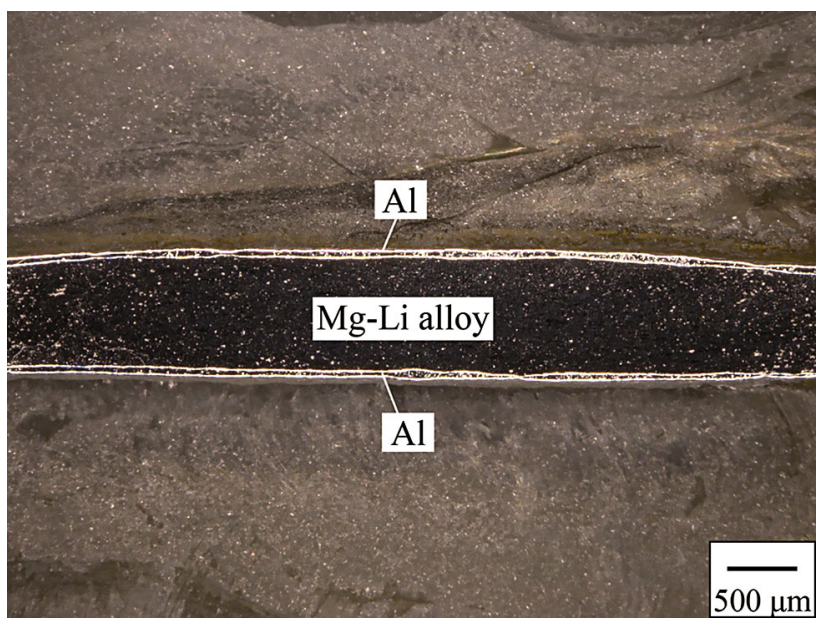

Fig. 14 Longitudinal section of tensile specimen of the as-rolled Alcoated $\mathrm{Mg}-\mathrm{Li}$ alloy sheet after a tensile elongation of $150 \%$ at $573 \mathrm{~K}$ at $0.001 \mathrm{~s}^{-1}$ in the air

outside atmosphere. In the air, oxidation takes place and it should weaken the substrate, where the crack generates and then cause a strain concentration there. Finally, a rapid fracture will occur after the crack appears. Differently, in an Ar atmosphere, the $\mathrm{Mg}-\mathrm{Li}$ alloy substrate will not suffer oxidation even if the crack appears on the Al coating, which mean that there is no strain concentration at the crack. Therefore, the specimen exhibits much larger elongation with many cracks on the $\mathrm{Al}$ coating.

These cracks on the Al coating should cause low corrosion resistance. In the previous study of our group, we investigated the elongation of an Al-coated AZ80 Mg alloy, which does not contain Li element. No crack was observed on the Al-coating surface even after a very large elongation of $550 \%$ at $573 \mathrm{~K}$ at $0.001 \mathrm{~s}^{-1}$ [20]. Therefore, the Li element is considered to be an important factor in the 


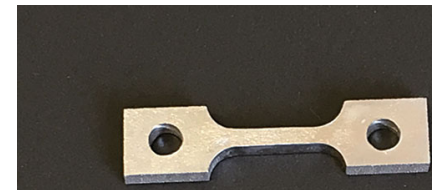

Undeformed ( $0 \%)$

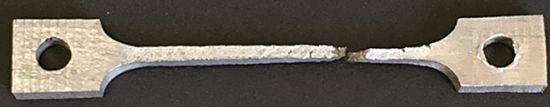

Deformed in the air $(200 \%)$

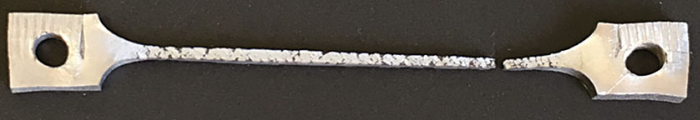

Deformed in an Ar atmosphere (400\%) $5 \mathrm{~mm}$

Fig. 15 Tensile specimens of the Al-coated $\mathrm{Mg}-\mathrm{Li}$ alloy at $573 \mathrm{~K}$ at $0.001 \mathrm{~s}^{-1}$ in the air and in an $\mathrm{Ar}$ atmosphere

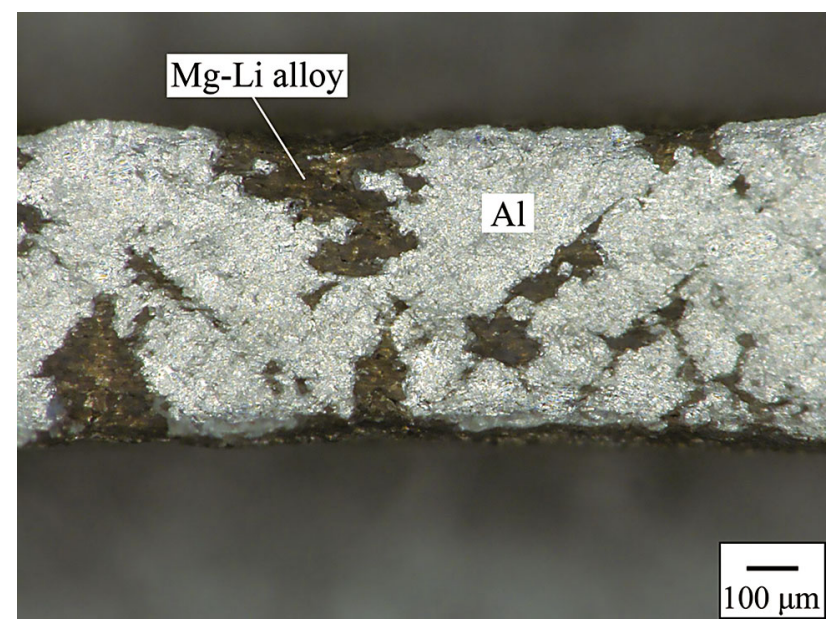

Fig. 16 Cracks on the $\mathrm{Al}$ coating along about $45^{\circ}$ to the tensile direction

crack formation in the present case. As shown in Fig. 9b, $\mathrm{Li}$ can diffuse far into the $\mathrm{Al}$ coating at high temperature. From these results, it can be considered that because of the high diffusivity of the $\mathrm{Li}$ atom, the pure $\mathrm{Al}$ became an $\mathrm{Al}-$ $\mathrm{Li}$ alloy with a small content of Li. Al-Li alloys are known to have anisotropic mechanical properties after rolling and it exhibits low yield strength in the directions of $45^{\circ}-60^{\circ}$ to the rolling direction [27]. In this study, crack formation in about $45^{\circ}$ to the tensile as well as rolling direction was observed on the Al-coating surface, as shown in Fig. 16. Therefore, cracks on the Al coating may be related to the diffusion of $\mathrm{Li}$ into the $\mathrm{Al}$-coating layer from the $\mathrm{Mg}-\mathrm{Li}$ alloy substrate.

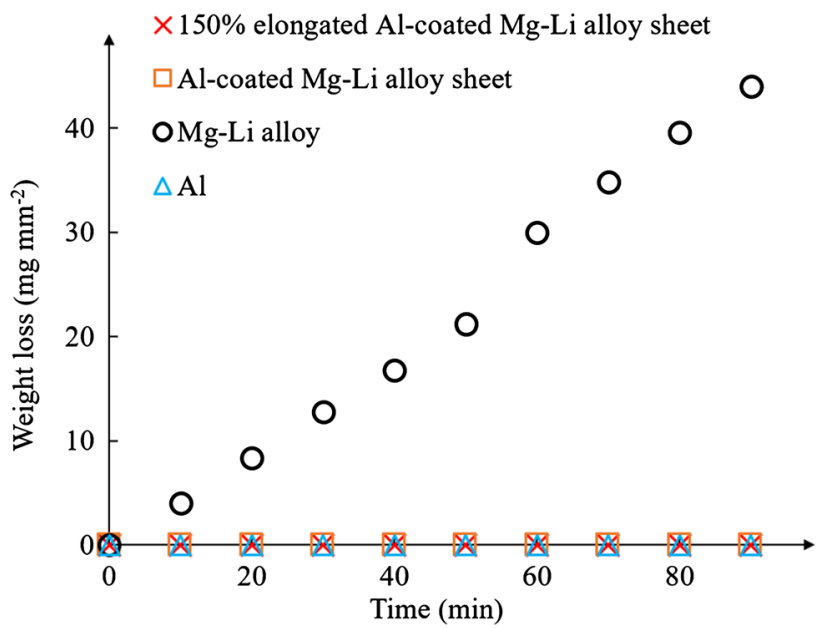

Fig. 17 Weight loss of different samples in 0.5 mass $\% \mathrm{HCl}$ aqueous solution

\subsection{Corrosion Resistance of the Al-Coated Mg-Li Alloy Sheet}

Figure 17 displays the weight losses of some different alloys during immersion in 0.5 mass $\% \mathrm{HCl}$ aqueous solution at room temperature. Without the $\mathrm{Al}$ coating, as marked by the circle, the $\mathrm{Mg}-\mathrm{Li}$ alloy reacts with the acid solution seriously and loses its weight very quickly. However, both the as-extruded and as-rolled Al-coated $\mathrm{Mg}-\mathrm{Li}$ alloy samples have no weight loss in the $\mathrm{HCl}$ solution, the same as the result of pure Al. Therefore, it has been demonstrated that an excellent corrosion resistance can be given to the $\mathrm{Mg}-\mathrm{Li}$ alloy by $\mathrm{Al}$ coating using the present hot extrusion method and that the further rolling process causes no adverse effect on the corrosion resistance of the Al-coated $\mathrm{Mg}-\mathrm{Li}$ alloy. Moreover, the as-rolled Alcoated $\mathrm{Mg}-\mathrm{Li}$ alloy specimen elongated to $150 \%$ at $573 \mathrm{~K}$ at $0.001 \mathrm{~s}^{-1}$ in the air also exhibits the same good corrosion resistance as the pure $\mathrm{Al}$. This requires the coating to exhibit a same elongation of $150 \%$ as the substrate to keep unbroken. In addition, this excellent ductility of the $\mathrm{Al}$ coating is revealed in the following investigation of the tensile properties.

\section{Conclusions}

1. An Al-coated $\mathrm{Mg}-8$ mass\% $\mathrm{Li}$ alloy rectangular bar was successfully fabricated by hot extrusion. A uniform and well bonded $\mathrm{Al}$ coating was produced with a thickness of approximately $200 \mu \mathrm{m}$. After rolled into thin sheet, the coating kept uniform thickness and the bonding between coating and substrate remained free from cracks. 
2. Tensile test of the as-rolled Al-coated $\mathrm{Mg}-8 \mathrm{Li}$ alloy sheet exhibited a fracture elongation of about $35 \%$ at room temperature at $0.001 \mathrm{~s}^{-1}$. There is no break at the bonding between the substrate and coating.

3. The as-rolled Al-coated $\mathrm{Mg}-\mathrm{Li}$ alloy sheet exhibited superplastic elongations of about $200 \%$ and $400 \%$ at $573 \mathrm{~K}_{\text {at }} 0.001 \mathrm{~s}^{-1}$ in the air and in an Ar atmosphere, respectively.

4. The Al-coated $\mathrm{Mg}-\mathrm{Li}$ alloy sheet exhibited excellent corrosion resistance in a 0.5 mass $\% \mathrm{HCl}$ aqueous solution. Even though after a large elongation of $150 \%$, this good corrosion was still kept.

Acknowledgements This work was partly supported by the Nanotechnology Platform Program (Molecule and Material Synthesis) of the Ministry of Education, Culture, Sports, Science and Technology (MEXT), Japan.

\section{References}

[1] T.M. Pollock, Science 328, 986 (2010)

[2] R. Wu, Y. Yan, G. Wang, L.E. Murr, W. Han, Z. Zhang, M. Zhang, Int. Mater. Rev. 2, 65 (2015)

[3] W.Q. Xu, N. Birbilis, G. Sha, Y. Wang, J.E. Daniels, Y. Xiao, M. Ferry, Nat. Mater. 14, 1229 (2015)

[4] A.A. Nayeb-Hashemi, J.B. Clark, A.D. Pelton, Bull. Alloys Ph. Diagr. 5, 365 (1984)

[5] T.T. Yin, R.Z. Wu, Z. Leng, G.J. Du, X.Y. Guo, M.L. Zhang, J.H. Zhang, Surf. Coat. Technol. 225, 119 (2013)

[6] Y. Zou, Z.W. Zhang, S.Y. Liu, D. Chen, G.X. Wang, Y.Y. Wang, M.L. Zhang, Y.H. Chen, J. Electrochem. Soc. 162, 64 (2015)
[7] G.X. Wang, M.L. Zhang, R.Z. Wu, Appl. Surf. Sci. 258, 2648 (2012)

[8] J.F. Li, Z.Q. Zheng, S.C. Li, W.D. Ren, Z. Zhang, Mater. Sci. Eng., A 433, 233 (2006)

[9] L.L. Gao, C.H. Zhang, M.L. Zhang, X.M. Huang, X. Jiang, J. Alloys Compd. 458, 789 (2009)

[10] J.E. Gray, B. Luan, J. Alloys Compd. 336, 88 (2002)

[11] H. Matsumoto, S. Watanabe, S. Hanada, J. Mater. Process. Technol. 169, 9 (2005)

[12] T. Tokunaga, K. Matsuura, M. Ohno, Mater. Trans. 53, 1134 (2012)

[13] H.P. Zhang, J.L. Yang, R.Z. Wu, T.Z. Wang, X.D. Dong, L.G. Hou, M.L. Zhang, S. Betsoten, B. Krit, Adv. Eng. Mater. 18, 1792 (2016)

[14] H.P. Yang, M.W. Fu, S. Tob, G.C. Wang, Mater. Des. 112, 151 (2016)

[15] X.H. Liu, G.J. Du, R.Z. Wu, Z.Y. Niu, M.L. Zhang, J. Alloys Compd. 509, 9558 (2011)

[16] F.R. Cao, J.Z. Cui, J.L. Wen, F. Lei, J. Mater. Sci. Technol. 16, 55 (2000)

[17] O.D. Sherby, J. Wadsworth, Prog. Mater Sci. 33, 169 (1989)

[18] A.J. Barnes, J. Mater. Eng. Perform. 16, 440 (2007)

[19] X.J. Wang, D.K. Xu, R.Z. Wu, X.B. Chen, Q.M. Peng, L. Jin, Y.C. Xin, Z.Q. Zhang, Y. Liu, X.H. Chen, G. Chen, K.K. Deng, H.Y. Wang, J. Mater. Sci. Technol. 34, 245 (2018)

[20] T. Tokunaga, K. Matsuura, M. Ohno, J. Alloys Compd. 601, 179 (2014)

[21] T.C. Xu, X.D. Peng, J. Qin, Y.F. Chen, Y. Yang, G.B. Wei, J. Alloys Compd. 639, 79 (2015)

[22] F.R. Cao, F. Xia, G.Q. Xue, Mater. Des. 92, 44 (2016)

[23] N. Chandra, Int. J. Non Linear Mech. 37, 461 (2002)

[24] P. Griffiths, C. Hammond, Scr. Met. 7, 793 (1973)

[25] A.B. Ma, Y. Nishida, N. Saito, I. Shigematsu, S.W. Lim, Mater. Sci. Technol. 19, 1642 (2003)

[26] X.H. Liu, H.B. Zhan, S.H. Gu, Z.K. Qu, R.Z. Wu, M.L. Zhang, Mater. Sci. Eng., A 528, 6157 (2011)

[27] N. Eswara Prasad, G. Malakondaiah, Bull. Mater. Sci. 15, 297 (1992) 